\title{
Electrochemically generated catalyst system with increased specificity and efficiency for olefin metathesis
}

\author{
Bülent Düz ${ }^{a}$, Kadir Pekmez ${ }^{a}$, Yavuz İmamoğlu ${ }^{a}{ }^{*}$, Șefik Süzer ${ }^{b}$, Attila Yıldız ${ }^{a}$ \\ ${ }^{a}$ Department of Chemistry, Hacettepe University, 06532 Beytepe, Ankara, Turkey \\ ${ }^{\mathrm{b}}$ Department of Chemistry, Bilkent University, 06533 Bilkent, Ankara, Turkey
}

Received 25 March 2003; received in revised form 24 April 2003; accepted 16 May 2003

Dedicated to Professor Ernst Otto Fischer on the occasion of his 85th birthday

\begin{abstract}
A facile route for the electrochemical generation of an olefin metathesis catalyst from methylene chloride solution of $\mathrm{WCl}_{6} \mathrm{was}$ described. It was found that reductive, oxidative and pulse electrolysis produced the same intermediate. This electrolysis intermediate incorporates olefin into its structure possibly forming a metal-olefin complex, which decomposes into catalytically active metal carbene type species. ESCA, NMR and ESR methods were used to elucidate the structure of the catalyst system. The catalyst was applied in the metathesis of 1-octene and 2-octene without any need for a co-catalyst. Highly specific products with high yields were obtained.
\end{abstract}

(C) 2003 Elsevier B.V. All rights reserved.

Keywords: Metathesis catalyst; Electrocatalysis; Tungsten hexachloride; 1-Octene; 2-Octene

\section{Introduction}

The catalyst systems for olefin metathesis reactions usually involve transition metal salts or oxides and their complexes [1-13]. These catalysts are generally used together with some co-catalysts such as organoaluminum compounds which produce the species specifically responsible for the catalytic action [3,4]. In most cases it is difficult to determine the coordination number and the oxidation state of these active species. Co-catalysts increase the activity of the catalysts used. They, on the other hand, cause a reduction in the stability and the selectivity of the catalyst. The loss of selectivity is due to side reactions such as isomerization, alkylation and

\footnotetext{
* Corresponding author. Tel.: +90-312-297-7955; fax: +90-312299-2163.

E-mail address: imamoglu@hacettepe.edu.tr (Y. İmamoğlu).
}

polymerization [14-17]. The extent of the side reactions can be reduced by the addition of some chemicals such as tertiary amines to the medium or by the optimization of the ratios of the catalyst to co-catalyst and to olefin [18]. The photochemical generation of catalytic action [19] without the need for a co-catalyst is possible but activity is reduced substantially in these cases [20].

It is known that the electrochemical reduction of $\mathrm{WCl}_{6}$ or $\mathrm{MoCl}_{5}$ using $\mathrm{Pt}$ cathode and $\mathrm{Al}$ anode in chlorinated solvents under controlled potential conditions produces a stable and active metathesis catalyst. The electrochemical control of the desired oxidation state of the active species thus leads to higher selectivity in metathesis reactions [21-24].

This study describes an investigation of the electrogeneration of an active, stable, efficient and selective catalytic system from the electrolysis of $\mathrm{WCl}_{6}$ in methylene chloride using a $\mathrm{Pt}$ cathode and $\mathrm{Al}$ anode. Oxidative, reductive and pulse electrolysis results are 
compared and an electrochemical formation mechanism for the catalyst system is proposed.

\section{Results and discussion}

The cyclic voltammogram of $\mathrm{WCl}_{6}$ in methylene chloride- $0.01 \mathrm{M}$ tetrabutylammonium tetrafluoroborate $\left(\mathrm{TBABF}_{4}\right)$ medium on a $\mathrm{Pt}$ disc electrode is shown in Fig. 1. The first and second reduction steps are easily observed with a peak potential of +0.9 and $-0.3 \mathrm{~V}$, respectively. Two oxidation peaks at +0.3 and $+1.6 \mathrm{~V}$ are observed when the potential scan is reversed. Constant potential electrolysis at more negative potential than $+0.9 \mathrm{~V}$ produces cathodic currents, whereas the same electrolysis at more positive potential than + $1.6 \mathrm{~V}$ results in anodic currents.

The cathodic peak at $+0.9 \mathrm{~V}$ is due to the one electron reduction of $\mathrm{WCl}_{6}$ Eq. (1) followed by the splitting of $\mathrm{WCl}_{6}{ }^{-}$in to $\mathrm{WCl}_{5}{ }^{\bullet}$ neutral radical and chloride ion Eq. (2)

$\mathrm{WCl}_{6}+\mathrm{e}^{-} \rightarrow \mathrm{WCl}_{6}^{\cdot-}$

$\mathrm{WCl}_{6}{ }^{-} \rightarrow \mathrm{WCl}_{5}{ }^{\bullet}+\mathrm{Cl}^{-}$

The anodic peak at $+1.6 \mathrm{~V}$, on the other hand, is due to the one electron oxidation Eq. (3) process producing

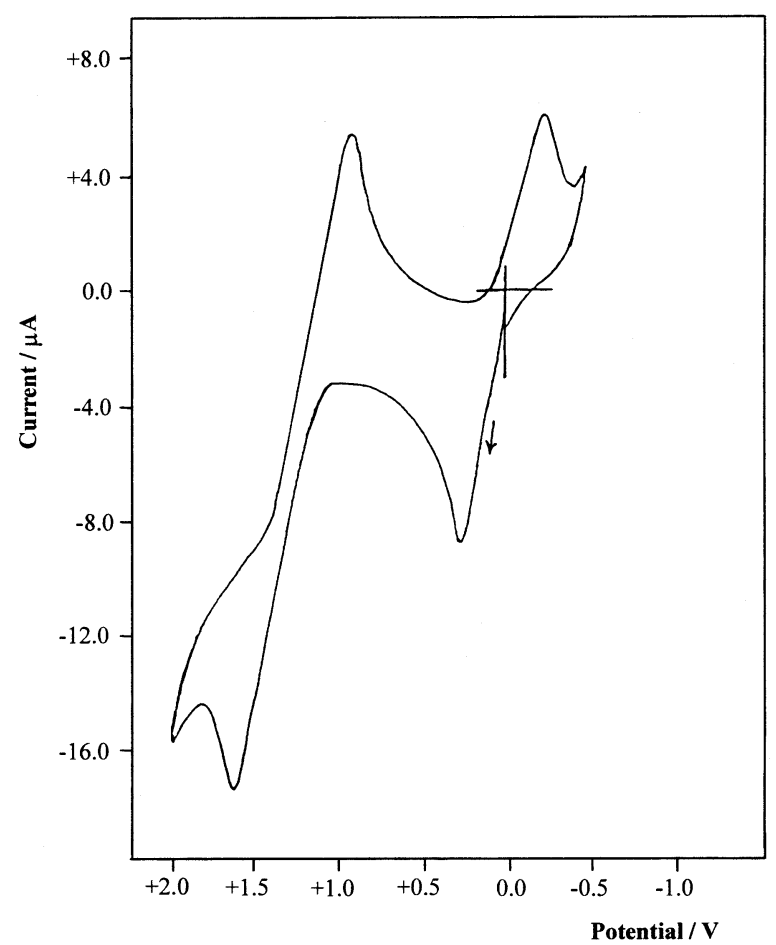

Fig. 1. Cyclic voltammogram of $1.0 \times 10^{-3} \mathrm{M} \mathrm{WCl}_{6}$ solution in methylene chloride- $0,01 \mathrm{M} \mathrm{TBABF}_{4}$ on $\mathrm{Pt}$ disc electrode. Scan rate: $100 \mathrm{mV} \mathrm{s}^{-1}$
$\mathrm{WCl}_{5}^{+}$(with the same oxidation state as $\mathrm{WCl}_{6}$ ) and chlorine atoms which dimerize to produce chlorine molecules Eq. (4).

$\mathrm{WCl}_{6} \rightarrow \mathrm{WCl}_{5}^{+}+\mathrm{Cl}^{\bullet}+\mathrm{e}^{-}$
$2 \mathrm{Cl}^{\bullet} \rightarrow \mathrm{Cl}_{2}$

The reductive electrolysis at $+0.9 \mathrm{~V}$ and the oxidative electrolysis at $+1.6 \mathrm{~V}$ both produced the catalytically active species in the metathesis of olefins. This result indicates that the species responsible for the catalytic activity must be generated at the $\mathrm{Al}$ counter electrode (anode) in one of the above electrolysis experiments since the products of these electrolysis are different in nature. The possible electrochemical reactions Eqs. (5)(7) occurring at the Al anode during the cathodic electrolysis at $\mathrm{Pt}$ electrode are,

$\mathrm{Cl}^{-} \rightarrow \mathrm{Cl}^{\bullet}+\mathrm{e}^{-}$

$\mathrm{Al}+3 \mathrm{Cl}^{-} \rightarrow \mathrm{AlCl}_{3}+3 \mathrm{e}^{-}$

$\mathrm{WCl}_{5} \cdot \rightarrow \mathrm{WCl}_{5}^{+}+\mathrm{e}^{-}$

During the oxidative electrolysis at $\mathrm{Pt}$ electrode the only possible electrochemical reaction Eq. (8) occurring at the $\mathrm{Al}$ counter electrode (cathode) is

$\mathrm{WCl}_{6}+\mathrm{e}^{-} \rightarrow \mathrm{WCl}_{5}{ }^{-}+\mathrm{Cl}^{-}$

The only common species produced during either of these electrolysis experiments is $\mathrm{WCl}_{5}^{+}$.

Another evidence for the crucial role of $\mathrm{WCl}_{5}^{+}$in the catalysis was obtained from the pulse electrolysis where the potential applied to the $\mathrm{Pt}$ electrode is pulsed between +0.6 and $+1.6 \mathrm{~V}$ (pulse duration $=$ $0.2 \mathrm{~s}$ ). As explained below the yield of the metathesis reaction is increased significantly during the pulse electrolysis. $\mathrm{WCl}_{5}{ }^{\circ}$ neutral radicals produced at the Pt cathode during the cathodic half cycle of the pulse, get oxidized immediately at the same surface during the subsequent half cycle of the pulse, producing $\mathrm{WCl}_{5}^{+}$. Furthermore $\mathrm{WCl}_{5}{ }^{\circ}$ neutral radical produced at the Al cathode during the first half cycle of the pulse gets oxidized to $\mathrm{WCl}_{5}^{+}$at the same surface during the following half cycle. The absence of any ESR signal indicated that $\mathrm{WCl}_{5}{ }^{\circ}$ neutral radical does not exist in the solution after a prolonged electrolysis. It can thus be concluded that $\mathrm{WCl}_{5}^{+}$is the only possible active species in the catalysis system. The counter ion which stabilizes $\mathrm{WCl}_{5}^{+}$in the electrolysis solution is probably produced from the reaction between the other electrolysis products such as $\mathrm{AlCl}_{3}$ and $\mathrm{Cl}^{-}$.

$\mathrm{AlCl}_{3}+\mathrm{Cl}^{-} \rightarrow \mathrm{AlCl}_{4}^{-}$

The accepted mechanism in literature for several olefin metathesis catalyst systems involve the initial formation of a metal-olefin complex intermediate via $\pi$-interaction which then gives a metal carbene structure by 1,2 hydride shift $[1,2]$ Eq. (10) 


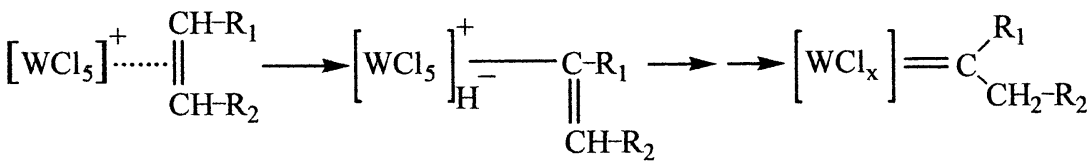

$\left(\mathrm{R}_{1}=\mathrm{H}\right.$, alkyl $; \mathrm{R}_{2}=$ alkyl $)$

The olefin metathesis proceeds via this metal carbene compound $[1,2]$ according to the well-known following step Eq. (11).
Fig. 2 shows the ESCA spectra of $\mathrm{WCl}_{6}$, the product obtained after the reductive electrolysis and the product after the olefin addition (before the metathetic activity

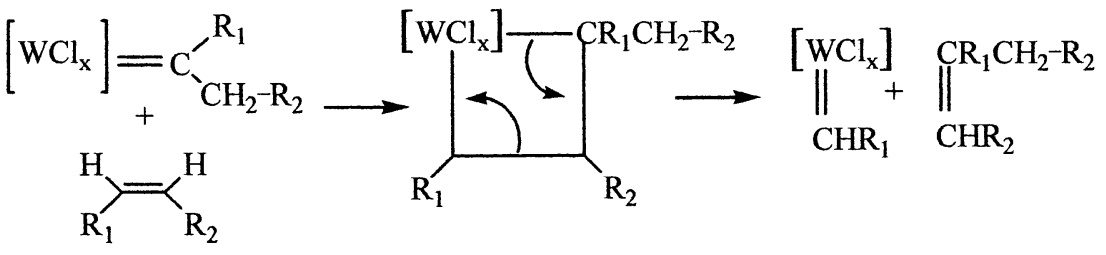

$\left(\mathrm{R}_{1}=\mathrm{H}\right.$, alkyl $\left.; \mathrm{R}_{2}=\mathrm{alkyl}\right)$

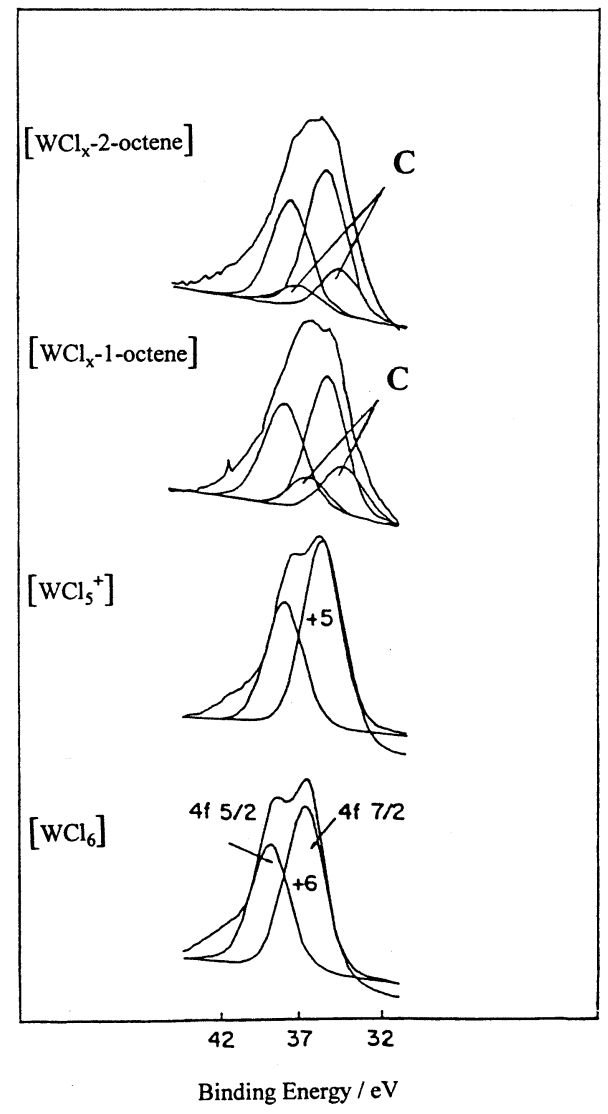

Fig. 2. W4f region of the XPS spectrum of $\mathrm{WCl}_{6}$, reduced or pulsed $\mathrm{WCl}_{6}$ and two olefin complexes. The extra peaks denoted by $\mathrm{C}$ correspond to $\mathrm{W}$-olefin adduct. starts; where olefin $\left./ \mathrm{WCl}_{6}=0.1\right)$. The binding energies of the $4 \mathrm{f}_{7 / 2}$ and $4 \mathrm{f}_{5 / 2}$ of $\mathrm{WCl}_{6}$ electrons (36.6 and $38.7 \mathrm{eV}$ ) are in good agreement with the literature values (36.4 and $38.5 \mathrm{eV}$ ) [25]. The binding energies of the $4 f_{7 / 2}$ and $4 \mathrm{f}_{5 / 2}$ electrons of a compound obtained after the reductive electrolysis however shifted to lower values by about $0.5 \mathrm{eV}$. For the olefin adduct, these energies are shifted toward even lower values by about $1.4 \mathrm{eV}$ (shown in the figure by $\mathrm{C}$ ), which shows that the electron density is altered significantly upon incorporation of an olefin into the structure of the tungsten complex.

The absence of the carbene type peaks $[26,27]$ in the ${ }^{1} \mathrm{H}-\mathrm{NMR}$ and ${ }^{13} \mathrm{C}$-NMR spectra obtained from the solution of olefin adduct indicates that the initial olefin adduct is likely a metal-olefin complex.

The solution obtained after the electrolysis of $\mathrm{WCl}_{6}$ is not active in initiating the metathesis reaction. Upon further addition of olefin to the solution containing the olefin adduct of the electrolyzed tungsten complex, the metathetic activity starts. (The olefin adduct can be kept under nitrogen atmosphere after the solvent is evaporated and is active even after a week when redissolved in dichloromethane).

The primary metathesis product obtained from 1octene is 7-tetradecene and that from 2-octene is 6dodecene (other products, ethylene and 2-butene, respectively, are vented off the vessel during the reaction). The metathetic activity obtained with the electrolysis solution leads to the formation of these products which 
underlines the high specificity of the reaction. Furthermore the yield of the formation of these products increases significantly if the initial electrolysis is carried out with the application of a pulse instead of a constant potential. For 2-octene the final yield of 6-dodecene was $92.7 \%$ in pulse electrolysis experiment while the final yield in constant cathodic potential electrolysis was $62.5 \%$ (Products yield: $2 \boldsymbol{n}_{\text {product }} /\left[\boldsymbol{n}_{\text {olefin }}\right]_{\mathrm{o}} \times 100$; the ratio of Olefin/Catal. $=80$; reaction time $3 \mathrm{~h}$ at room temperature). It should also be noted that a much less amount of catalyst is needed with electrolyzed solutions when compared with photochemical systems [20], wherein no co-catalyst is required.

In another experiment, an in situ reductive electrolysis of $\mathrm{WCl}_{6}$-olefin mixture was carried out. Fig. 3A shows the product distribution obtained after such an electrolysis with 1-octene which is initially present in the $\mathrm{WCl}_{6}$ solution. The chromatogram shown in Fig. 3B is the one obtained after 1-octene is added to the solution after $\mathrm{WCl}_{6}$ was electrolyzed. Comparison of the two product distributions clearly indicates that the addition of olefin to the solution after electrolysis is more advantageous. The loss of the specificity in the in situ electrolysis is probably due to the further reduction of the intermediates formed between the initial electrolysis product of $\mathrm{WCl}_{6}$ and the olefin present in solution.

\section{Conclusion}

In this electrochemical system, the mechanism proposed in Eq. (10) involving the addition of $\mathrm{WCl}_{5}^{+}$to the alkene followed by 1,2 hydride shift for the first metalcarbene formation is in good agreement with the experimental results. It can be concluded that the catalyst system which is electrochemically generated from $\mathrm{WCl}_{6}$ solution in dichloromethane acts with higher specificity and is more efficient. The efficiency of the catalyst system is remarkably increased when generated using pulse electrolysis.

\section{Experimental details}

\subsection{Reagents}

Olefins were purchased from Aldrich, stored over $\mathrm{KOH}$ and then distilled over $\mathrm{CaH}_{2}$ under nitrogen atmosphere. $\mathrm{WCl}_{6}$ was purified by sublimation of the more volatile impurities $\left(\mathrm{WO}_{2} \mathrm{Cl}_{2}\right.$ and $\left.\mathrm{WClO}_{4}\right)$ under nitrogen at about $200{ }^{\circ} \mathrm{C}$ and kept under nitrogen atmosphere [5]. Methylene chloride was washed with concentrated sulfuric acid, then with aqueous carbonate solution and water, followed by drying over calcium chloride [16]. It was then distilled over $\mathrm{P}_{2} \mathrm{O}_{5}$ under nitrogen, kept under nitrogen.

\subsection{Electrochemical procedure and apparatus}

The electrochemical measurements were carried out under nitrogen atmosphere in a three-electrode cell having a jacket through which water from a constant temperature bath was circulated. A polished $\mathrm{Pt}$ disc electrode with a diameter of $0.10 \mathrm{~cm}$, inlaid in a glass capillary of $0.80 \mathrm{~cm}$, was used in cyclic voltammetric experiments as a working electrode. The counter electrode was a $\mathrm{Pt}$ wire $\left(2 \mathrm{~cm}^{2}\right)$ immersed in $\mathrm{CH}_{2} \mathrm{Cl}_{2} / 0.1 \mathrm{M}$ $\mathrm{TBABF}_{4}$ separated from the electrolysis solution by a sintered glass disc. The reference electrode consisted of $\mathrm{AgCl}$ coated on a $\mathrm{Ag}$ wire in $\mathrm{CH}_{2} \mathrm{Cl}_{2} / 0.1 \mathrm{M} \mathrm{TBABF}_{4}$
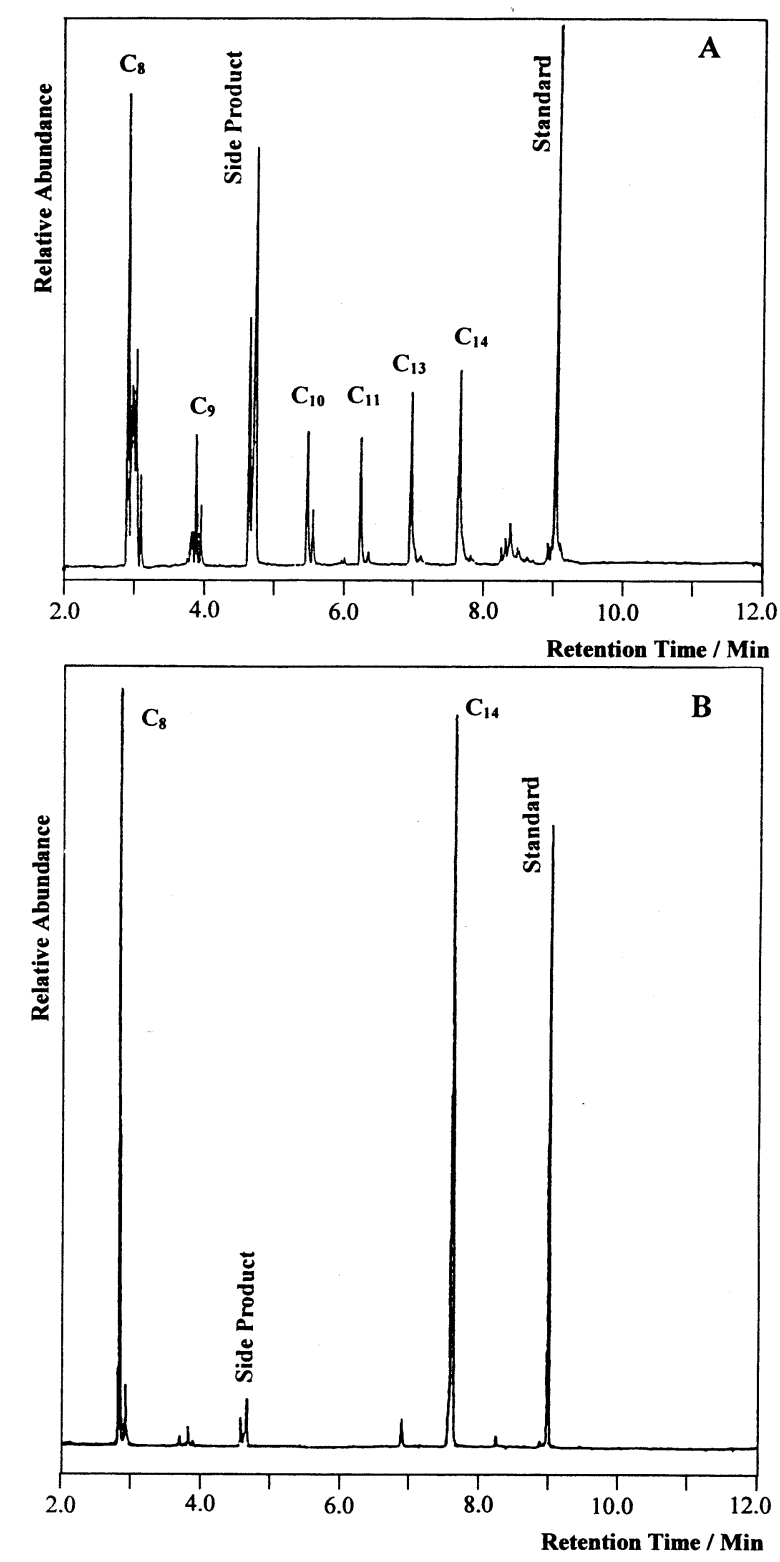

Fig. 3. Gas chromatograms of the solution taken after the solution of (A) $\mathrm{WCl}_{6}$-olefin mixture is reductively electrolyzed, (B) $\mathrm{WCl}_{6}$ is reductively electrolyzed and excess olefin is added following electrolysis. 
which was also separated from the electrolysis solution by a sintered glass disc.

Exhaustive controlled potential and pulse electrolysis experiments were carried out in an undivided cell with a macro working $\mathrm{Pt}$ foil electrode $\left(2.0 \mathrm{~cm}^{2}\right)$ and a $\mathrm{Al}$ foil $\left(2.0 \mathrm{~cm}^{2}\right)$ counter electrode. Macro electrolysis was carried out without supporting electrolyte due to its deleterious effect on the catalyst system. For this reason the distance between $\mathrm{Pt}$ working and $\mathrm{Al}$ counter electrode was kept constant and as small as possible (i.e. $2.0 \mathrm{~mm}$ ) in order to keep the solution resistance at minimum. The electrodes were introduced into the deep red solution $\left(10^{-2} \mathrm{M} \mathrm{WCl}_{6}\right.$ in $\left.\mathrm{CH}_{2} \mathrm{Cl}_{2}\right)$ and electrolysis was conducted for $3 \mathrm{~h}$ in all reductive, oxidative and pulse experiments. The colour of the resulting solutions was darkened after each electrolysis. An aliquot from this solution was added to the certain amount of olefin along with internal standard (hexadecane) under nitrogen flow. The reactions were then followed by GC-MS.

\subsection{Analysis}

Electrochemical instrumentation consisted of EGGPAR Model 273 coupled with a PAR Model Universal Programmer. Current voltage curves were recorded on a Model SE-790 BBC Goerzt Metra-Watt X-Y recorder.

Analysis of the products was performed on a Hewlett Packard Model 5890 GC which was connected to Model 5971 MSD analyser. Separations were performed on 25 $\mathrm{mm} \times 30 \mathrm{~m}$ glass capillary columns supported with DB5 polysiloxane.

ESR measurements were obtained with a VARIAN E-L9 X-band ESR spectrometer with a $100 \mathrm{kHz}$ modulation at room temperature.

NMR spectra were obtained with BRUKER GmbH DPX-400, $400 \mathrm{MHz}$ High Performance Digital FTNMR Spectrometer.

A KRATOS ES 300 photoelectron spectrometer with Mgkalfa X-rays was used for ESCA.

\section{Acknowledgements}

A.Y. thanks Alexander von Humboldt Foundation for the donation of the electrochemical instruments.

\section{References}

[1] K.J. Ivin (Ed.), Olefin Metathesis, Academic Press, London, 1983.

[2] K.J. Ivin, J.C. Mol (Eds.), Olefin Metathesis and Metathesis Polymerization, Academic Press, London, 1997.

[3] W.J. Feast, V.C. Gibson, In: F.R. Hartley (ed.) The Chemistry of the Metal-Carbon Bond, vol. 5, John Wiley and Sons Ltd., 1989, p. 205.

[4] N. Calderon, H.Y. Chen, K.W. Scott, Tetrahedron Lett. (1967) 3327.

[5] N. Calderon, E.A. Ofstead, J.P. Ward, W.A. Judy, K.W. Scott, J. Am. Chem. Soc. 90 (1968) 4133.

[6] J.L. Wang, H.R. Menapace, J. Org. Chem. 33 (1968) 3794.

[7] J.C. Mol, J.A. Moulijn, C. Boelhouwer, J. Chem. Soc. Chem. Commun. (1968) 633.

[8] M. Leconte, J.M. Basset, Ann. N.Y. Acad. Sci. 383 (1980) 165.

[9] J.H. Wengrovius, R.R. Schrock, M.R. Churchill, J.R. Missert, W.J. Youngs, J. Am. Chem. Soc. 102 (1980) 4515.

[10] R.R. Schrock, S. Rocklage, J.H. Wengrovius, G. Rupprecht, J. Fellman, J. Mol. Catal. 8 (1980) 73.

[11] C.P. Casey, T.S. Burkhardt, J. Am. Chem. Soc. 95 (1973) 5833.

[12] P.R. Sharp, D. Astruc, R.R. Schrock, J. Organomet. Chem. 182 (1979) 477.

[13] R.R. Schrock, R.T. DePue, J. Feldman, C.J. Schaverien, J.C. Dewan, A.H. Lui, J. Am. Chem. Soc. 110 (1988) 1423.

[14] E.A. Zuech, J. Chem. Soc. Chem. Commun. (1968) 1182.

[15] E.A. Zuech, W.B. Hughes, D.H. Kubicek, E.T. Kittleman, J. Am. Chem. Soc. 92 (1970) 532.

[16] A. Uchida, Y. Hamano, Y. Mukai, S. Matsuda, Ind. Eng. Chem. Prod. Res. Dev. 10 (1971) 372.

[17] Y. Uchida, M. Hidai, T. Tatsumi, Bull. Chem. Soc. Jpn 45 (1972) 1158.

[18] K. Ichikawa, K. Fukuzumi, J. Org. Chem. 41 (1976) 2633.

[19] P. Krausz, F. Garnier, J.E. Dubois, J. Am. Chem. Soc. 97 (1975) 437.

[20] B. Zümreoglu-Karan, Y. Imamoglu, J. Mol. Catal. 65 (1991) 329.

[21] M. Gilet, A. Mortreux, J. Nicole, F. Petit, J. Chem. Soc. Chem. Commun. (1979) 521.

[22] M. Gilet, A. Mortreux, J.C. Folest, F. Petit, J. Am. Chem. Soc. 105 (1983) 3876.

[23] O. Dereli, B. Düz, B. Zümreoglu-Karan, Y. Imamoglu, Appl. Organometal. Chem. 17 (2003) 23.

[24] S. Çetinkaya, B. Düz, Y. Imamoglu, Appl. Organometal. Chem. 17 (2003) 232.

[25] P.G. Gassman, D.W. Macomber, S.M. Willging, J. Am. Chem. Soc. 107 (1985) 2380.

[26] J. Kress, J.A. Osborn, J. Chem. Soc. Chem. Commun. (1982) 514.

[27] J. Kress, J.A. Osborn, R.M.E. Greene, K.J. Ivin, J.J. Rooney, J. Chem. Soc. Chem. Commun. (1985) 874. 